\title{
Early apoptosis in different models of cardiac hypertrophy induced by high renin-angiotensin system activity involves CaMKII
}

\author{
J. Omar Velez Rueda, Julieta Palomeque, and Alicia Mattiazzi \\ Centro de Investigaciones Cardiovasculares, Consejo Nacional de Investigaciones Científicas y Técnicas-La Plata, Facultad \\ de Medicina, Universidad Nacional de La Plata, La Plata, Argentina
}

Submitted 8 November 2011; accepted in final form 3 April 2012

Rueda JO, Palomeque J, Mattiazzi A. Early apoptosis in different models of cardiac hypertrophy induced by high renin-angiotensin system activity involves CaMKII. J Appl Physiol 112: 2110-2120, 2012. First published April 5, 2012; doi:10.1152/japplphysiol.01383.2011.—The objective of this study was to establish whether 1 ) hyperactivity of renin-angiotensin-aldosterone system (RAAS) produces apoptosis in early stages of cardiac disease; and 2) $\mathrm{Ca}^{2+}$-calmodulin-dependent protein kinase II (CaMKII) is involved in these apoptotic events. Two models of hypertrophy were used at an early stage of cardiac disease: spontaneously hypertensive rats (SHR) and isoproterenol-treated rats (Iso-rats). At 4 mo, SHR showed blood pressure, aldosterone serum levels, used as RAAS activity index, and left ventricular mass index, used as hypertrophy index, above control values by $84.2 \pm 2.6$ $\mathrm{mmHg}, 211.2 \pm 25.8 \%$, and $8.6 \pm 1.1 \mathrm{mg} / \mathrm{mm}$, respectively. There was also an increase in apoptotis (Bax-to-Bcl-2 ratio and terminal deoxynucleotidyl transferase dUTP-mediated nick-end labeling positive cells) associated with an enhancement of CaMKII activity with respect to age-matched controls (phosphorylated-CaMKII, $98.7 \pm$ 14.1 above control). Similar results were observed in 4-mo-old Isorats. Cardiac function studied by echocardiography remained unaltered in all groups. Enalapril treatment significantly prevented hypertrophy, apoptosis, and CaMKII activity. Moreover, intracellular $\mathrm{Ca}^{2+}$ handling in isolated myocytes was similar between SHR, Iso-rats, and their aged-matched controls. However, SHR and Iso-rats showed a significant increase in superoxide anion generation (lucigenin) and lipid peroxidation (thiobarbituric acid reactive substance). In transgenic mice with targeted cardiomyocyte expression of a CaMKII inhibitory peptide (AC3-I) or a scrambled control peptide (AC3-C), Iso treatment increased thiobarbituric acid reactive substance in both strains, whereas it increased CaMKII activity and apoptosis only in AC3-C mice. Endogenous increases in RAAS activity induce ROS and CaMKII-dependent apoptosis in vivo. CaMKII activation could not be associated with intracellular $\mathrm{Ca}^{2+}$ increments and was directly related to the increase in oxidative stress.

angiotensin II; $\mathrm{Ca}^{2+}$-calmodulin-dependent protein kinase II; reactive oxygen species; hypertrophy; apoptosis

EXPERIMENTAL EVIDENCE INDICATES that a critical factor in the transition from compensated to noncompensated cardiac hypertrophy is myocyte cell loss by apoptosis and necrosis (42). The circulating levels of angiotensin II (ANG II) are increased in heart failure and may constitute one of the major causes of cell death in this transition (27). Moreover, activation of the multifunctional $\mathrm{Ca}^{2+}$-calmodulin protein kinase II (CaMKII), which $\delta$-isoform is largely predominant in mammalian myocardium (46), is a typical finding in heart failure from different etiologies. Activation of this kinase also constitutes a main step in the signaling cascade that leads to apoptosis following

Address for reprint requests and other correspondence: J. Palomeque, Centro de Investigaciones Cardiovasculares, Facultad de Medicina, La Plata, Buenos Aires 1900, Argentina (e-mail: julip@aetos.med.unlp.edu.ar). several cardiac insults, like reperfusion injury (39), ionomycin, high extracellular $\mathrm{K}^{+}$concentration, intracellular acidosis, and oxidative stress $(28,32,47)$. Furthermore, intracellular reactive oxygen species (ROS) levels increase dramatically in models of structural heart disease (18), particularly those initiated by ANG II (35). In recent in vitro experiments, our laboratory described an apoptotic pathway that involves increases in ROS produced by ANG II and activation of CaMKII (28). Exogenous ANG II administration has also been linked to CaMKII and apoptosis in vivo (11). Whether these events can also be triggered by exacerbated endogenous ANG II production and which is their impact, if any, on cardiac function, remains unclear.

It has been shown that spontaneously hypertensive rats (SHR), one of the most used models for hypertrophy and heart failure studies, have high activity of the renin-angiotensinaldosterone system (RAAS) (45) and increased CaMKII expression (17). Hagemann et al. (17) described that CaMKII $\delta$ is overexpressed in hearts from adult SHR. Furthermore, normotensive rats treated with high doses of isoproterenol (Iso), also show high activity of RAAS (16). However, a possible association between endogenous levels of ANG II in different early stage models of exacerbated RAAS activity and CaMKIIinduced apoptosis has not been previously studied. Moreover, the functional consequences of RAAS exacerbation in early stages of heart disease are an uncharted territory. Taking advantage of these models, the present experiments were undertaken to investigate the early repercussion of high RAAS activity on CaMKII activation, apoptosis, and cardiac function.

\section{METHODS}

Animals and protocols. All procedures followed during this investigation conform to the Guide for the Care and Use of Laboratory Animals published by the US National Institutes of Health (NIH Publication no. 85-23, revised 1996), and the experimental protocol was approved by the Animal Welfare Committee of La Plata School of Medicine.

Male SHR and normotensive aged-matched control Wistar rats were used. At $3 \mathrm{mo}$, a group of SHR was treated with $10 \mathrm{mg} \cdot \mathrm{kg}^{-1} \cdot \mathrm{day}^{-1}$ enalapril, an inhibitor of the angiotensin converting enzyme (ACE), in the drinking water for $1 \mathrm{mo}$.

Normotensive Wistar rats were treated at 3 mo with two subcutaneous injections of $250 \mathrm{mg} / \mathrm{kg}$ Iso, separated by a 24-h interval, according to a previously described protocol (34), to induce cardiac damage $(3,4,30)$. Iso solution was prepared with sterile distilled acid water, to prevent Iso oxidation, immediately before injection. Control rats were injected with the solution without the drug. The rats treated with Iso were further randomly assigned to receive enalapril (Ena) (Iso-Ena rats) (at the doses and way mentioned for SHR) or no drug (Iso-rats). An additional group of rats, receiving only Ena (Ena rats), was used as control. All treatments were performed for 1 mo. 
Before and after the treatment, the animals were weighed, the systolic blood pressure was measured by the tail-cuff method, and echocardiographic examination was performed. Rats were then killed, the heart was weighed, and the tibia length (TL) was measured. Hearts were assigned for biochemical studies, immunohistochemical staining, ROS production determinations, or myocyte isolation for contractile and intracellular $\mathrm{Ca}^{2+}$ concentration $\left(\left[\mathrm{Ca}^{2+}\right]_{\mathrm{i}}\right)$ measurements.

Additionally, transgenic mice with cardiomyocyte-delimited transgenic expression of either a CaMKII inhibitory peptide (AC3-I) or a scrambled control peptide (AC3-C) were used. Breeding mates of these mice were generously supplied by Dr. Mark Anderson (University of Iowa) and reproduced and genotyped in our laboratory. The mice were treated as the Iso-rats, i.e., animals were killed 1 mo after injections, and the hearts were used for measuring ROS, CaMKII activity, and apoptosis.

Aldosterone plasma levels. Aldosterone plasma levels were used as an index of ANG II plasma levels (21) and RAAS activity. Blood samples were centrifuged at $13,500 \mathrm{rpm}$ for $15 \mathrm{~min}$, and the plasma was stored at $-80^{\circ} \mathrm{C}$ until analysis. The plasma aldosterone concen- tration was measured by standard radioimmunoassay method, according to manufacturer instructions.

Echocardiographic examination. Echocardiogram was performed in each rat under light anesthesia ( $35 \mathrm{mg} / \mathrm{kg}$ ip pentobarbital sodium). Cardiac geometry and function were evaluated by two-dimensional M-mode echocardiography with a 7-MHz linear transducer. All measurements, including left ventricular (LV) wall thickness and diastolic dimensions, were performed according to the American Society of Echocardiography method (31). LV mass was calculated as previously described (24).

Myocyte isolation. Rats were anesthetized by intra-abdominal injection of pentobarbital sodium, and myocytes were isolated by enzymatic digestion (29) and kept in a HEPES buffered solution at room temperature $\left(20-22^{\circ} \mathrm{C}\right)$, until used.

$\left[\mathrm{Ca}^{2+}\right]_{i}$ and cell shortening. Isolated myocytes were loaded with fura $2-\mathrm{AM}(10 \mu \mathrm{mol} / 1$ for $15 \mathrm{~min}) .\left[\mathrm{Ca}^{2+}\right]_{\mathrm{i}}$ was measured with an epifluorescence system (Ion Optix, Milton, MA). Briefly, dye-loaded cells were placed in a chamber on the stage of an inverted microscope (Nikon.TE 2000-U) and continuously superfused with a HEPES
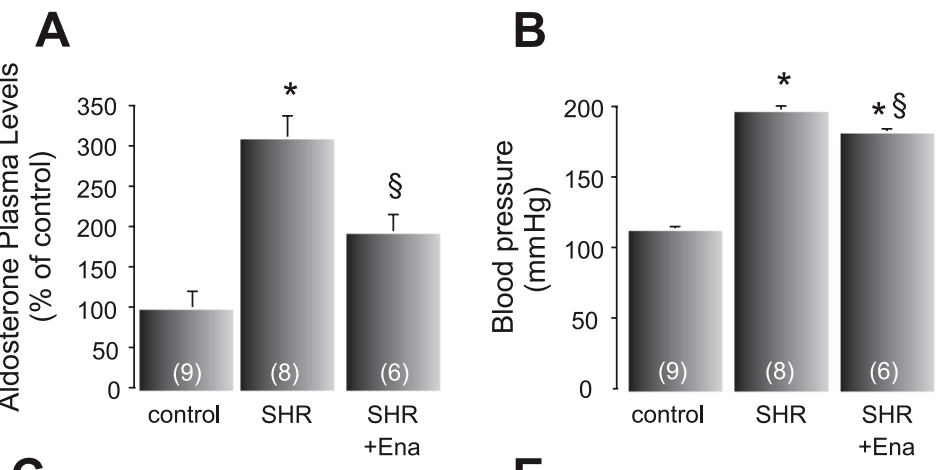

\section{D}
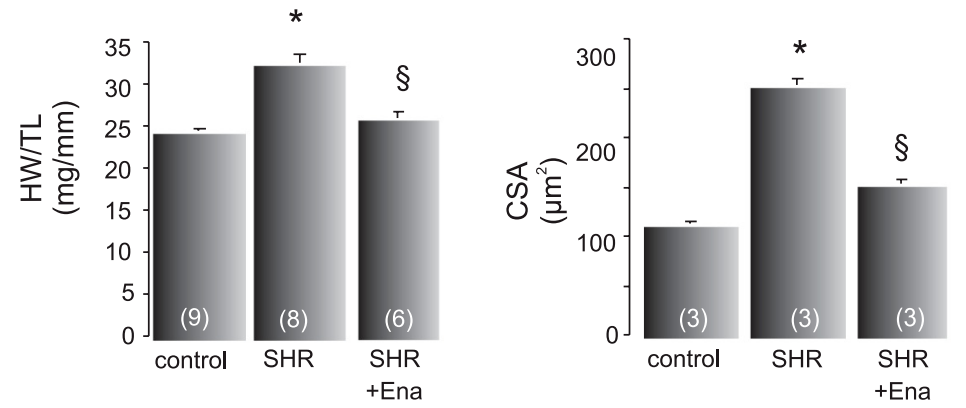

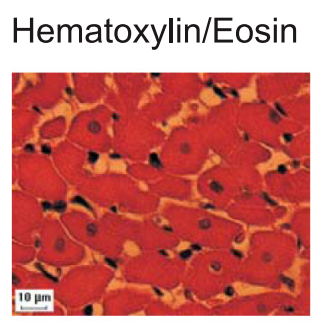

control

\section{$\mathbf{F}$} Echocardiography

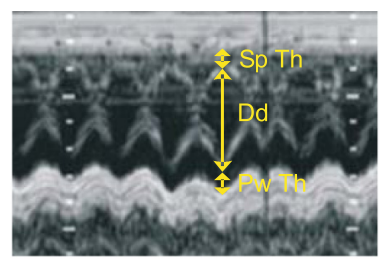

control

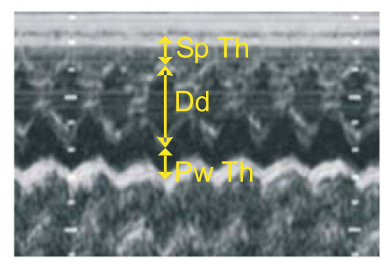

SHR

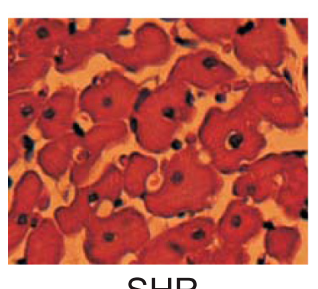

SHR

+ Ena

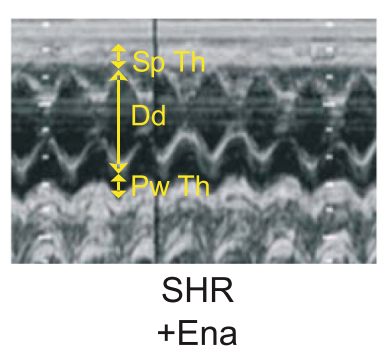

(9)

control

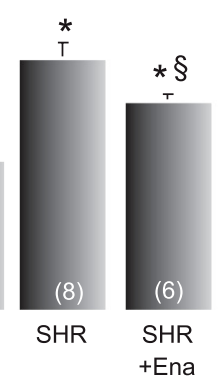

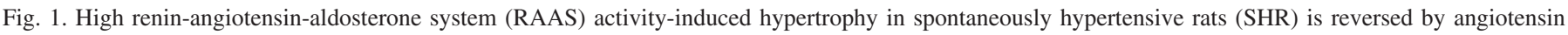

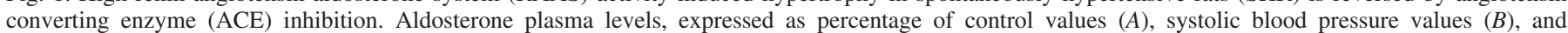

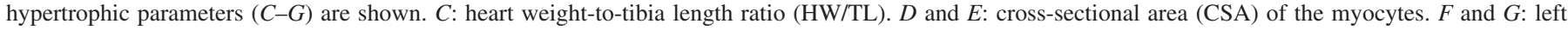

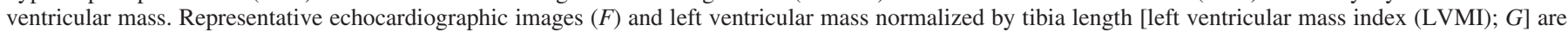

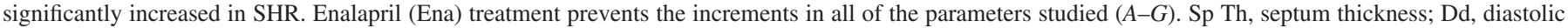

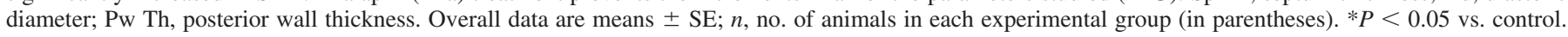
$\S P<0.05+$ Ena vs. SHR. 
Table 1. Echocardiographic parameters from control rats, SHR, and SHR treated with enalapril

\begin{tabular}{lccc}
\hline \hline & Control & SHR & SHR+Enalapril \\
\hline$n$ & 9 & 8 & 6 \\
LVDD, mm & $5.59 \pm 0.32$ & $6.44 \pm 0.16$ & $6.07 \pm 0.11$ \\
STh, mm & $1.52 \pm 0.03^{*}$ & $1.85 \pm 0.03^{*}$ & $1.71 \pm 0.02^{*}$ \\
LVPWTh, mm & $1.55 \pm 0.02^{*}$ & $1.92 \pm 0.06^{*}$ & $1.70 \pm 0.03^{*}$ \\
ES, \% & $60.76 \pm 0.89$ & $60.87 \pm 0.46$ & $61.39 \pm 1.34$ \\
MVS, \% & $30.60 \pm 1.51$ & $30.53 \pm 0.96$ & $30.66 \pm 0.77$ \\
LVMI & & & \\
$\quad$ mg/g & $1.39 \pm 0.09^{*}$ & $2.61 \pm 0.12^{*}$ & $2.04 \pm 0.05^{*}$ \\
$\quad \mathrm{mg} / \mathrm{mm}$ & $12.79 \pm 1.05^{*}$ & $21.43 \pm 1.15^{*}$ & $17.81 \pm 0.39^{*}$ \\
\hline
\end{tabular}

Values are means \pm SE; $n$, no. of rats. SHR, spontaneously hypertensive rats; LVDD, left ventricular diastolic diameter; STh, septum thickness; LVPWTh, left ventricular posterior wall thickness; ES, endocardial shortening; MVS, midwall ventricular shortening; LVMI, left ventricular mass index. $* P<0.05$ vs. all others groups.

buffered solution at a constant flow of $1 \mathrm{ml} / \mathrm{min}$ at room temperature $\left(20-22^{\circ} \mathrm{C}\right)$. Myocytes were stimulated via two-platinum electrodes on either side of the bath at $0.5 \mathrm{~Hz}$. Fura 2 fluorescence was taken as an index of the $\left[\mathrm{Ca}^{2+}\right]_{\mathrm{i}}$. Resting cell length and cell shortening were measured by a video-based motion detector (Ion Optix). Fluorescence and cell shortening data were stored for off-line analysis (ION WIZARD fluorescence analysis software).

ROS determinations: superoxide anion production. Cardiac tissue slices from the LV $(1-5 \mathrm{~mm})$ were obtained and kept at $4^{\circ} \mathrm{C}$ until assayed as previously described. Cardiac slices were kept in the assay buffer during $30 \mathrm{~min}$ in a metabolic incubator before superoxide anion $\left(\mathrm{O}_{2}{ }^{-}\right)$production was measured by the lucigenin $(5 \mu \mathrm{mol} / \mathrm{l})$-enhanced chemiluminescence method, after $20 \mathrm{~min}$ of incubation with lucigenin, as previously described (8). The lucigenin-containing assay buffer with tissue slices minus background was recorded. $\mathrm{O}_{2}{ }^{--}$production was normalized to milligrams per dry weight per minute. The increases in $\mathrm{O}_{2}{ }^{--}$production were expressed as differences from control values.

Lipid peroxidation. Lipid peroxidation was determined by measuring the rate of production of thiobarbituric acid reactive substances (TBARS), expressed as nanomoles per milligram protein. Heart homogenates were centrifuged at $2,000 \mathrm{~g}$ for $10 \mathrm{~min}$. Supernatants $(0.5$ $\mathrm{ml}$ ) were mixed with $1.5 \mathrm{ml}$ trichloroacetic acid $(30 \% \mathrm{wt} / \mathrm{vol})$ and 0.5 $\mathrm{ml}$ water, followed by boiling for $15 \mathrm{~min}$. After cooling, absorbance was determined spectrophotometrically at $535 \mathrm{~nm}$, using a $\epsilon$ value of $1.56 \times 105 \mathrm{mmol} \cdot \mathrm{l}^{-1} \cdot \mathrm{cm}^{-1}$ (5).

Western blot. Hearts were freeze-clamped and pulverized. Briefly, $0.1 \mathrm{~g}$ of tissue was homogenized in four volumes of lysis buffer (in mmol/l, $30 \mathrm{KH}_{2} \mathrm{PO}_{4}, 25 \mathrm{NaF}, 300$ sucrose, 0.1 EDTA plus proteases inhibitor cocktail). Protein was measured by the Bradford method using BSA as standard. Lysates ( $\sim 90 \mu \mathrm{g}$ of total protein) were separated per gel line in 10\% SDS polyacrilamide gel (26) and transferred to polyvinylidene difluoride membranes. Blots were probed overnight with the following antibodies: Bcl-2 (Santa Cruz), Bax (Santa Cruz), caspase-3 (Chemicon), phosphorylated CaMKII (P-CaMKII) 1:1,000 (Abcam,), CaMKII 1:1,000 (Santa Cruz), $\mathrm{Thr}^{17}$-phosphorylated $\left(\mathrm{P}-\mathrm{Thr}^{17}\right.$ ) of phospholamban (PLN) 1:5,000 (Badrilla, Leeds, UK), PLN 1:5,000 (Badrilla, Leeds, UK). CaMKIIס, PLN, and GAPDH signals were used to normalize the signal intensity of the different proteins, as it is mentioned in RESULTS. Immunoreactivity was visualized by a peroxidase-based chemiluminescence detection kit (Amersham Biosciences) using a Chemidoc Imaging system. The signal intensity of the bands in the immunoblots was quantified by densitometry, using Image $\mathrm{J}$ software (National Institutes of Health). Some proteins, i.e., Bcl-2, could appear as one or two bands. It has been suggested that more than one band may correspond to differentially phosphorylated forms or cleavage products $(6,23$, $44)$. Due to this variation, we quantify the intensity of the two bands together when they appear.

Apoptosis assays. Apoptosis was determined by terminal deoxynucleotidyl transferase dUTP-mediated nick-end labeling (TUNEL) assay (In Situ Cell Death Detection Kit, TMR red, Roche, Mannheim, Germany). The TUNEL-positive cells were imaged under a fluorescence microscope $(\times 200$ magnification $)$ and counted in 10 random fields for each experimental situation. The results were expressed as percentage of TUNEL-positive cells related to total number of cells. 4',6-Diamidino-2-phenylindole dihydrochloride (1 $\mu \mathrm{g} / \mathrm{ml}$, Sigma, St. Lous, MO) was used for nuclear staining. Apoptotic cell death was also assessed by immunoblotting, as described above, as the increase in the ratio between the apoptotic signals Bax and the anti-apoptotic signal Bcl-2 and the enhancement in the amount of the $17-\mathrm{kDa}$ cleavage product of caspase-3, indicating caspase-3 activation (28).

Exercise tolerance. Rats were pretested for their treadmill running willingness at constant velocity of $15 \mathrm{~m} / \mathrm{min}$ without slope, until animals became exhausted or until they completed a 15-min period.

Statistics. All data are means \pm SE. Comparisons within groups were made by either paired or unpaired Student's $t$-test, as appropri-
Fig. 2. Ena blunts $\mathrm{Ca}^{2+}$-calmodulin-dependent protein kinase II (CaMKII) activity in SHR. A: typical blots of the phosphorylated form of CaMKII (P-CaMKII) and of its substrate, phospho-Thr ${ }^{17}$ residue of phospholamban (PLN; $\mathrm{P}-\mathrm{Thr}^{17}$ ) in control rats, SHR, and SHR treated with Ena. Total CaMKIIS and PLN expression are also shown. SHR depicted an increment in both phosphorproteins, and the treatment with Ena prevented both phosphorylations. $B$ : average data of these experiments. The signals of P-CaMKII and P-Thr ${ }^{17}$ were normalized by their total respective proteins. These experiments revealed that CaMKII is being activated by ANG II. Values are means $\pm \mathrm{SE} ; n$, no. of animals in each experimental group (in parentheses). $* P<0.05$ vs. control. $\S P<0.05,+$ Ena vs. SHR.
A
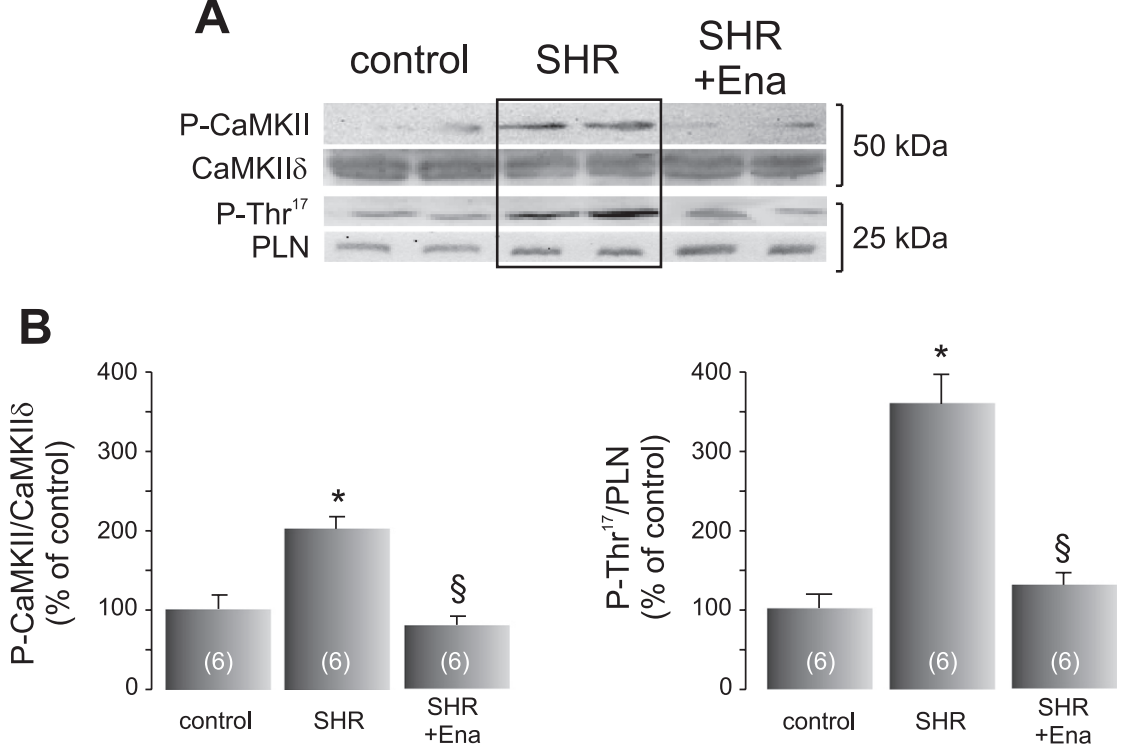
A
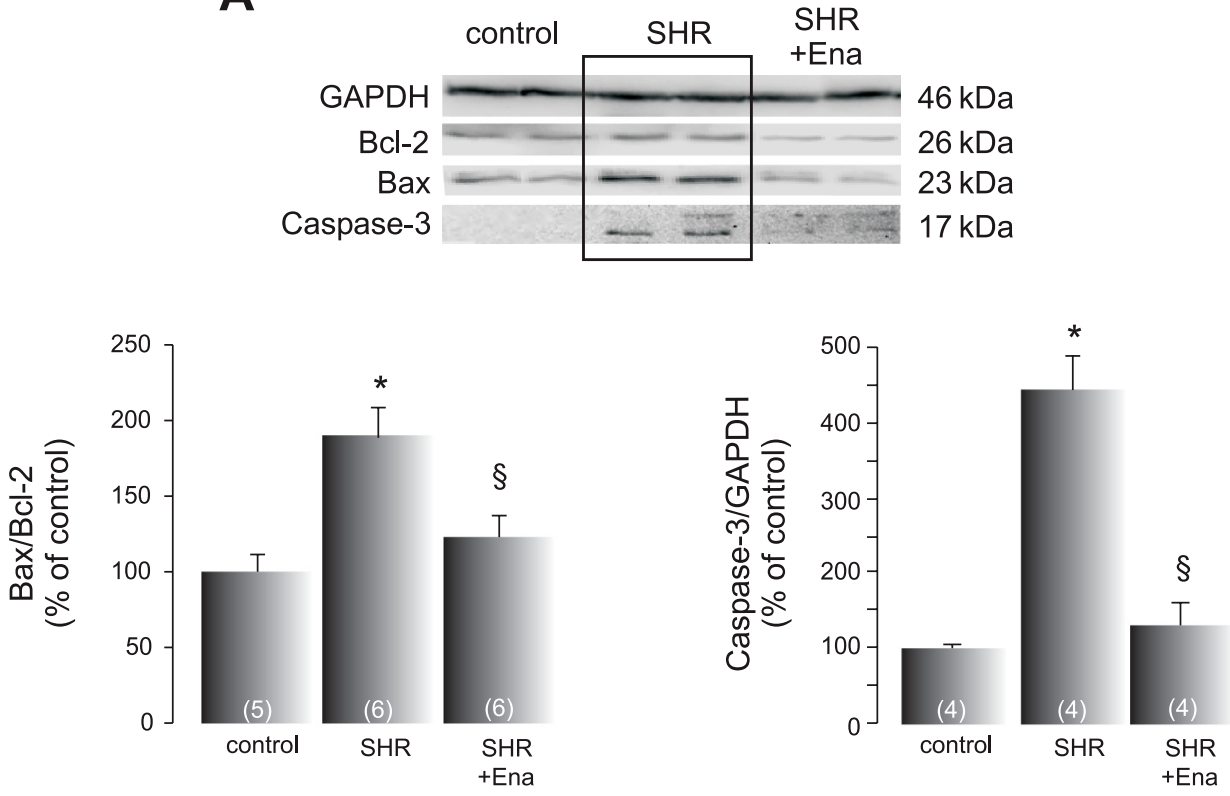

Fig. 3. Cardiac apoptosis in SHR is prevented by Ena. A: representative blots and average data of the proapoptotic and antiapoptotic proteins Bax and Bcl-2, respectively, and the 17-kDa cleavage product of caspase-3 from control rats, SHR, and SHR treated with Ena. GAPDH signals were used as loading controls. The increased ratio $\mathrm{Bax} / \mathrm{Bcl}-2$, used as an apoptotic index, and caspase-3 activation in SHR, are prevented by Ena treatment. $B$ : typical photographs of terminal deoxynucleotidyl transferase dUTP-mediated nick-end labeling (TUNEL) assay and 4',6-di-

B
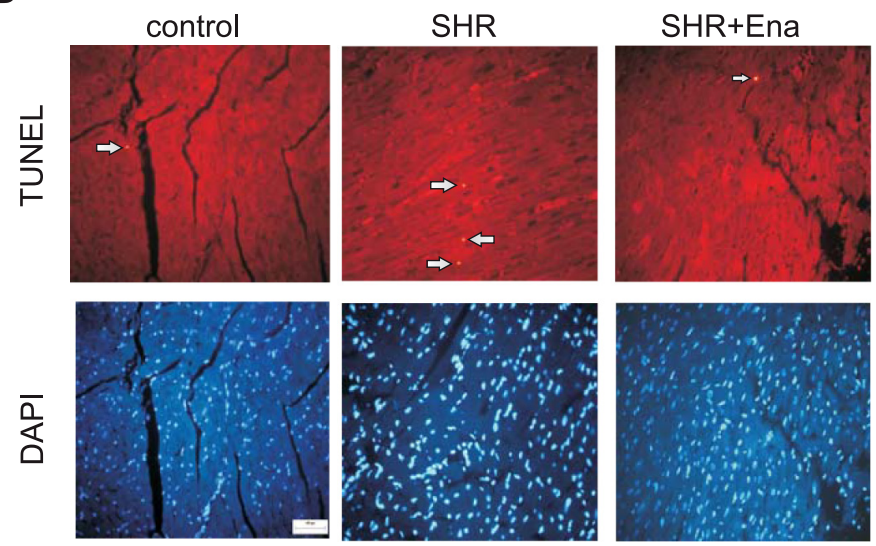
amidino-2-phenylindole dihydrochloride (DAPI) staining of control, SHR, and SHR treated with Ena. The mean values of TUNEL-positive cells normalized by total DAPI-stained nuclei in the bar graph below indicate that the increment in apoptosis in SHR is prevented by blocking RAAS axis. Values are means $\pm \mathrm{SE} ; n$, no. of animals in each experimental group (in parentheses). $* P<0.05$ vs. control. $\S P<0.05$, +Ena vs. SHR.

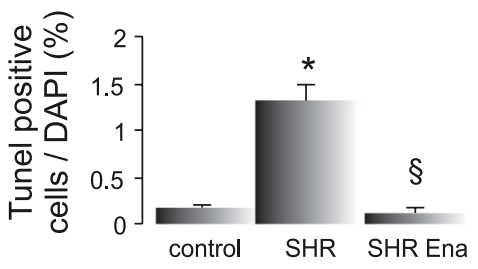

(4)

(4)

(4)

ate. One-way ANOVA was used for multigroup comparisons. The Newman-Keuls test was used to examine statistical differences observed with ANOVA. A value of $P<0.05$ was taken to indicate statistical significance.

\section{RESULTS}

High RAAS activity-induced cardiac hypertrophy and apoptosis in SHR is associated with CaMKII activation. Aldosterone plasma levels and blood pressure were significantly increased in 4-mo-old SHR with respect to age-matched normo- tensive control rats (Fig. 1, $A$ and $B$ ). Moreover, Fig. 1, $C-G$, shows that SHR developed hypertrophy, as indicated by the increase in the heart weight-to-TL ratio (HW/TL), the crosssectional area of the myocytes and the LV mass index (LVMI) evaluated by echocardiography (see also Table 1). Representative images of echocardiography and LV specimens obtained from each experimental group are shown in the right panels of Fig. $1(D$ and $F)$. As shown in the examples of Fig. $1 F$ and Table 1, although hypertrophy is present in SHR (increase in septum thickness, posterior wall thickness, and LVMI), no 

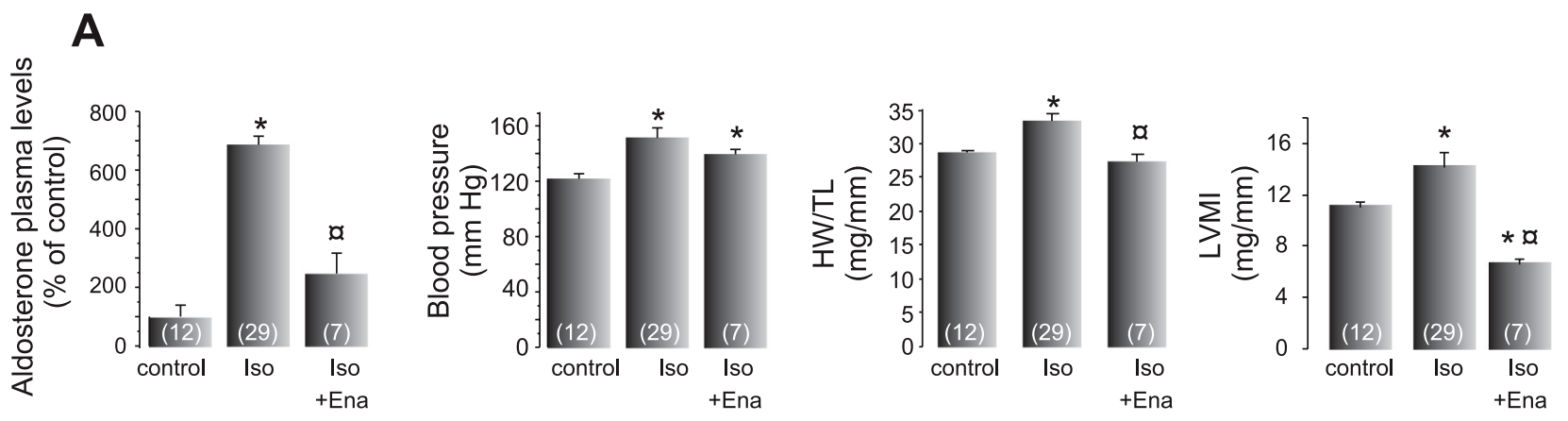

B

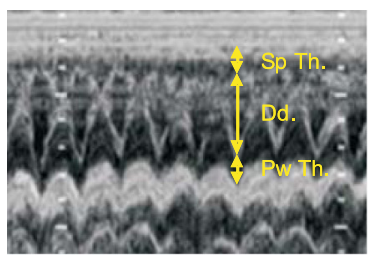

control

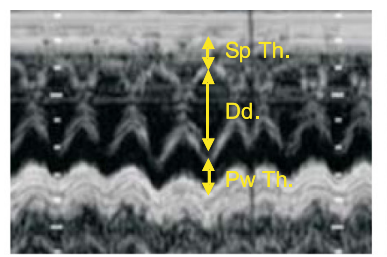

Iso

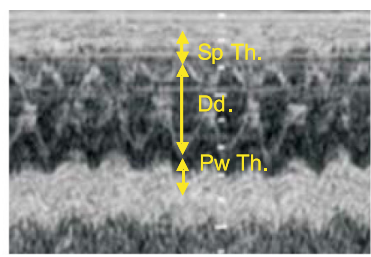

Iso+Ena

C
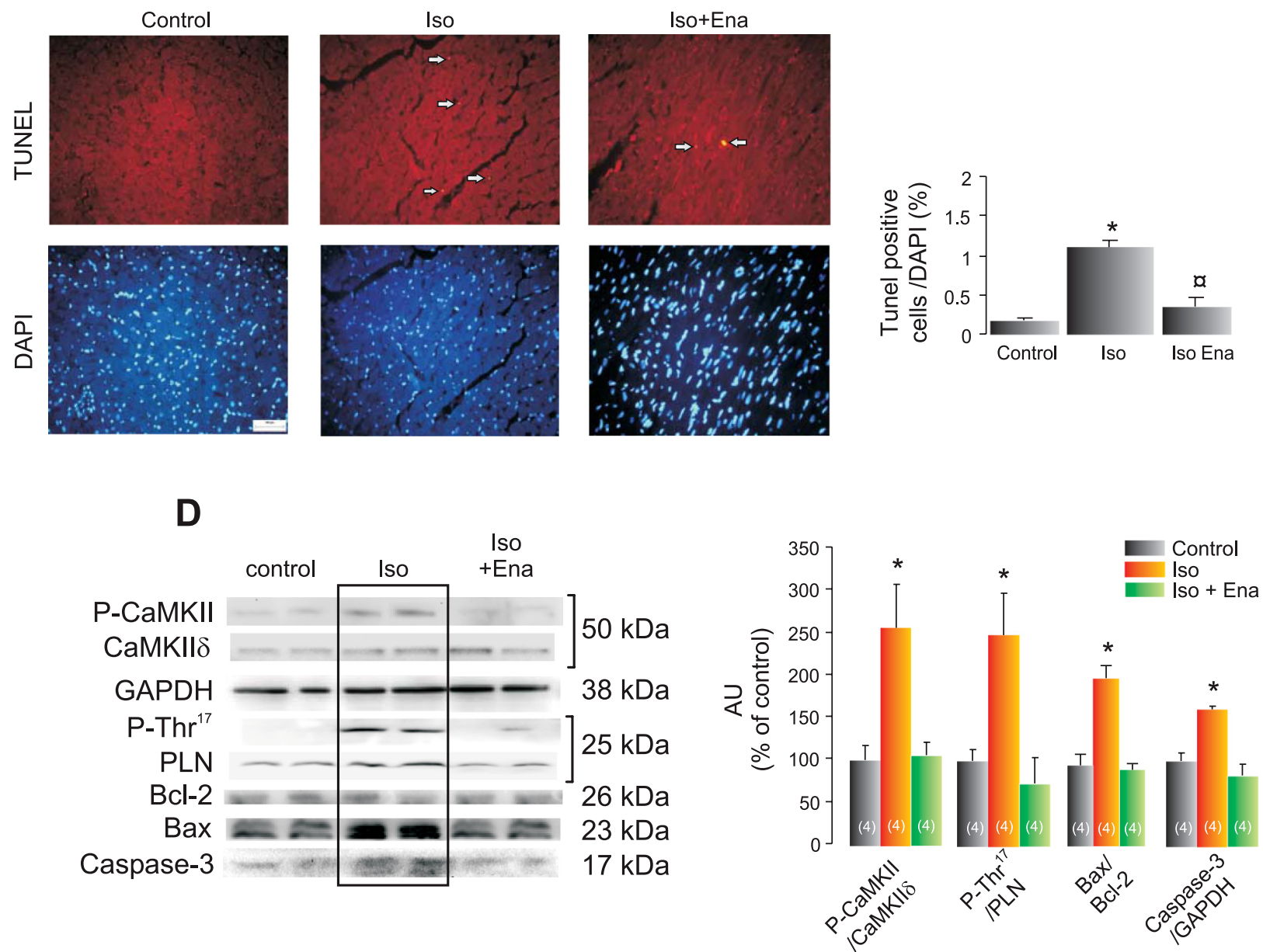
Table 2. Echocardiographic parameters from control rats, isoproterenol rats, and isoproterenol rats treated with enalapril

\begin{tabular}{|c|c|c|c|c|}
\hline & Wistar & Wistar Isoproterenol & Wistar+Enalapril & Wistar Isoproterenol+Enalapril \\
\hline$n$ & 12 & 29 & 4 & 7 \\
\hline LVDD, mm & $5.20 \pm 0.13 *$ & $5.81 \pm 0.07 *$ & $3.72 \pm 0.12 *$ & $4.43 \pm 0.23 *$ \\
\hline STh, mm & $1.54 \pm 0.03 \ddagger$ & $1.64 \pm 0.02 \dagger$ & $1.26 \pm 0.02 \dagger 屯$ & $1.23 \pm 0.05 t+$ \\
\hline LVPWTh, mm & $1.56 \pm 0.02 \ddagger$ & $1.70 \pm 0.02 \dagger$ & $1.24 \pm 0.02 \dagger+$ & $1.22 \pm 0.04 \dagger+$ \\
\hline $\mathrm{ES}, \%$ & $60.76 \pm 0.70$ & $59.86 \pm 0.40$ & $58.98 \pm 1.0$ & $58.52 \pm 0.86$ \\
\hline MVS, $\%$ & $30.16 \pm 1.32$ & $33.03 \pm 0.90$ & $33.1 \pm 1.02$ & $34.52 \pm 0.91$ \\
\hline \multicolumn{5}{|l|}{ LVMI } \\
\hline $\mathrm{mg} / \mathrm{g}$ & $1.38 \pm 0.08$ & $1.91 \pm 0.04 \dagger$ & $1.70 \pm 0.04 \dagger$ & $1.71 \pm 0.04 \dagger \dagger$ \\
\hline $\mathrm{mg} / \mathrm{mm}$ & $11.18 \pm 0.47 \ddagger$ & $14.28 \pm 0.36 \dagger$ & $5.16 \pm 0.06 \dagger t$ & $6.76 \pm 0.91 \dagger t$ \\
\hline
\end{tabular}

Values are means $\pm \mathrm{SE}$; $n$, no. of rats. $* P<0.05$ vs. all others groups. $\dagger P<0.05$ vs. Wistar rats. $\ddagger P<0.05$ vs. Wistar isoproterenol rats.

signs of pump failure were detected, i.e., there were no significant changes in LV diastolic diameter and endocardial and midwall shortening (Table 1). Similarly, the ergometric test was similar between SHR and control rats, i.e., rats stopped running after $8.37 \pm 0.82$ vs. $8.25 \pm 0.88$ min, respectively.

Ena treatment of SHR prevented the increase in aldosterone plasma levels, indicating the inhibition of RAAS, and slightly but significantly decreased blood pressure (Fig. 1, $A$ and $B$ ). Moreover, the increase in hypertrophic parameters (HW/TL, cross-sectional area, and LVMI) was also prevented by ACE inhibition (Fig. 1, $C-G$, and Table 1).

Figure 2 shows typical blots and average results of PCaMKII and total CaMKII $\delta$, and one of its typical substrates, $\mathrm{P}-\mathrm{Thr}^{17}$ of PLN, and total PLN. There was a significant increment in CaMKII and $\mathrm{Thr}^{17}$ phosphorylation in SHR, indicative of CaMKII activation, that was prevented by Ena treatment.

Typical blots and average data of the proapoptotic and antiapoptotic proteins Bax and Bcl-2, respectively, the 17-kDa cleavage product of caspase-3 and TUNEL staining (Fig. 3, A and $B$, respectively) indicated a significantly higher degree of apoptosis in SHR than in age-matched controls that was prevented by ACE inhibition.

The increase in RAAS produced by Iso treatment induces apoptosis and CaMKII activation in rat hearts. We also investigated whether CaMKII was implicated in inducing apoptosis in another high RAAS activity model produced after 1 mo of Iso treatment $(4,16,30)$.

As in the case of SHR, high doses of Iso induced an increase in aldosterone plasma levels, blood pressure, and hypertrophy (increased HW/TL relationship and LVMI) (Fig. 4, $A$ and $B$ ) without significant signs of heart failure in the echocargraphic recordings (endocardial and midwall ventricular shortening remains unaltered, Table 2). Moreover, the ergometric test was not different between Iso-rats and their controls $(8.50 \pm 0.93$ vs. $8.37 \pm 0.82 \mathrm{~min})$. Treatment of the animals with Ena significantly decreased the aldosterone plasma levels, indicat- ing blockade of the RAAS. Although blood pressure tended to decrease in the Ena-treated group, this decrease did not reach significance. In turn, hypertrophy present in the Iso-rats was prevented by ACE inhibition (Fig. 4, $A$ and $B$, and Table 2). Consistent with the results obtained in SHR, Fig. 4, $C$ and $D$, shows that apoptosis (increased TUNEL-positive cells, Bax/ Bcl-2 ratio, and caspase- 3 activation) and the increased CaMKII activity induced by Iso treatment (CaMKII and $\mathrm{Thr}^{17}$ site of PLN phosphorylations) were prevented by ACE inhibition with Ena.

Taken together, these results indicate that the enhancement of RAAS in SHR and Iso-rats is associated with a significant increase in CaMKII activity and apoptosis, suggesting a possible causal link between both events in vivo. It is worth noting that, despite the structural remodeling and apoptosis observed, heart function remains preserved in these rats.

CaMKII activity in high RAAS activity models is associated with ROS production and not with $\left[\mathrm{Ca}^{2+}\right]_{i}$ increases. CaMKII activation is conventionally associated with $\left[\mathrm{Ca}^{2+}\right]_{\mathrm{i}}$ increments. Moreover, recent experiments have emphasized the importance of ROS in the activation of the kinase [see for review, Erikson et al. (10)]. We, therefore, explored $\left[\mathrm{Ca}^{2+}\right]_{\mathrm{i}}$ handling and ROS production in an attempt to elucidate the source of CaMKII activation in our models.

We first assessed $\left[\mathrm{Ca}^{2+}\right]_{\mathrm{i}}$ handling in isolated myoytes from both high RAAS activity models. Figure $5 A$ shows typical superimposed records of cellular shortening and $\left[\mathrm{Ca}^{2+}\right]_{\mathrm{i}}$ transients (CaiT) of the SHR (red traces) and their normotensive controls (black traces). The average results (Fig. 5B) show that no differences were detected between both groups in contraction amplitude, CaiT, and sarcoplasmic reticulum $\mathrm{Ca}^{2+}$ content, assessed by the amplitude of the caffeine-induced CaiT. Moreover, diastolic and systolic $\mathrm{Ca}^{2+}$ did not reach significant difference between SHR and their controls. Mean values were $1.124 \pm 0.035$ and $1.571 \pm 0.059$ for control vs. $1.053 \pm$ 0.031 and $1.556 \pm 0.060$ for SHR, for diastolic and systolic Fura 2-AM fluorescence, respectively. Similar results were

\footnotetext{
Fig. 4. Ena treatment prevents isoproterenol (Iso)-induced hypertrophy, CaMKII activation, and apoptosis. A: from left to right, aldosterone plasma levels, blood pressure, and the hypertrophic indexes, HW/TL and the LVMI, measured by echocardiography, from control rats, Iso, and Iso+Ena treated rats. All of the parameters show an increment in Iso-rats that is prevented by the cotreatment with Ena. $B$ : representative echocardiographic images of the groups examined in A. $C$ : TUNEL and DAPI photographs of the different groups and mean values of these experiments, indicating an increment in TUNEL-positive cells normalized by total DAPI-stained nuclei, only in Iso-rats. $D$ : typical blots and average data of P-CaMKII and its substrate, P-Thr ${ }^{17}$ of PLN; of apoptotic and anti-apoptotic proteins, Bax and Bcl-2, respectively; and of active caspase-3 from control, Iso, and Iso+Ena groups. Total CaMKII $\delta$, PLN, and GAPDH are also shown. Iso treatment induces an increase in CaMKII activity (P-CaMKII and $\mathrm{P}-\mathrm{Thr}^{17}$ ), in the apoptotic index (Bax-to-Bcl-2 ratio) and in caspase-3 activation, which are prevented by Ena treatment. These groups of experiments link the increase in RAAS activity with apoptosis and CaMKII activation. AU, arbitrary units. Values are means $\pm \mathrm{SE} ; n$, no. of animals in each experimental group (in parentheses). ${ }^{*} P<0.05$ vs. control. $\propto P<0.05$, + Ena vs. Iso.
} 


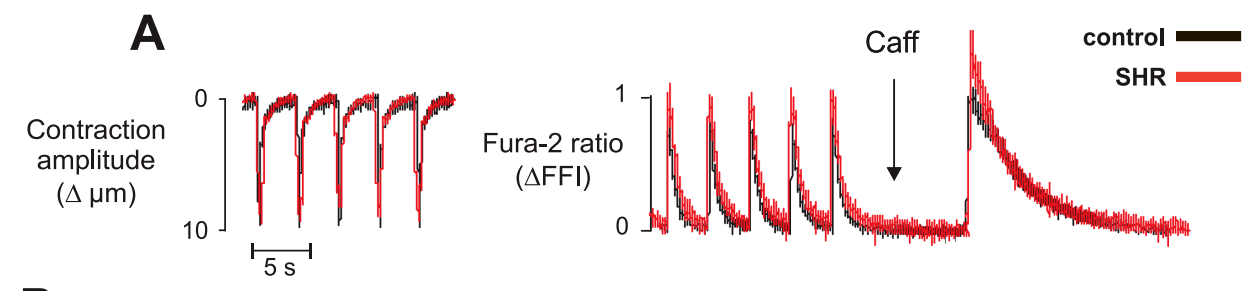

Fig. 5. Unaltered $\mathrm{Ca}^{2+}$ handling in control rats, SHR, and Iso-treated rats. A: representative superimposed recording of cell length and intracellular $\mathrm{Ca}^{2+}$ concentration transients (CaiT) from isolated myocytes of control rats (black trace) and SHR (red trace). The contraction amplitude and the CaiT amplitude under field-stimulated conditions $(0.5 \mathrm{~Hz})$ or under caffeine pulse $(25$ $\mathrm{mmol} / \mathrm{l})$ were not different between the strains. $\Delta \mathrm{FFI}$, change in Fura 2 fluorescence intensity. $B$ : average data of these experiments. $C$ : mean values of these parameters comparing control with Iso-rats. There were no significant differences in any of the variables studied between SHR or Iso-rats with respect to their controls. Values are means $\pm \mathrm{SE} ; n$, no. of myocytes in each experimental group (in parentheses).
B
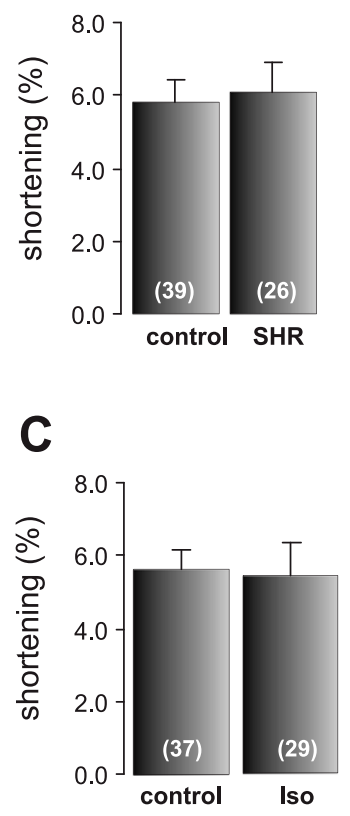
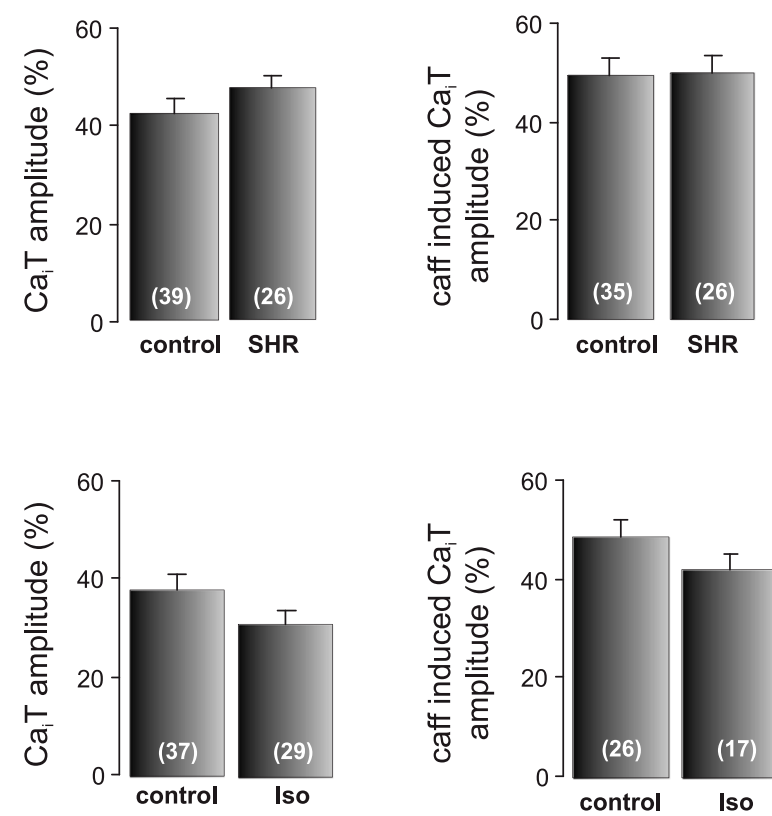

obtained when Iso-rats were compared with their controls. As shown in Fig. $5 C$, there were no differences between Iso and control rats in the contraction amplitude, CaiT amplitude, or in the sarcoplasmic reticulum $\mathrm{Ca}^{2+}$ content, suggesting that global $\mathrm{Ca}^{2+}$ levels underlying each contractile cycle do not differ between the two groups. These results are in agreement with the absence of signs of cardiac dysfunction (Tables 1 and 2 and the ergometric test). The absence of difference in $\mathrm{Ca}^{2+}$ handling confirms in in vivo models our previous in vitro and ex vivo findings, where CaMKII was activated by ANG II in the absence of detectable increases in $\left[\mathrm{Ca}^{2+}\right]_{\mathrm{i}}(28)$.

In a second set of experiments, we estimated oxidative stress by measuring $\mathrm{O}_{2}{ }^{--}$production and lipid peroxidation in SHR, Iso-rats, and their controls. Figure $6 \mathrm{~A}$ shows the increment in $\mathrm{O}_{2}{ }^{--}$generation measured by using lucigenin chemiluminescence in SHR and Iso-rats with respect to control rats. Accordingly, TBARS, used to determine lipid peroxidation, also increased in SHR and Iso-rats compared with their controls (Fig. 6B). Taken together, these results indicated that the increase in CaMKII activity in these two models of exacerbated RAAS cannot be associated with an enhanced $\left[\mathrm{Ca}^{2+}\right]_{\mathrm{i}}$ and occurs together with an increase in ROS production.

Targeted cardiac inhibition of CaMKII prevents apoptosis but does not inhibit ROS production in Iso-treated mice. To verify a possible causal link between ROS production, CaMKII activation, and apoptosis, we used mice with cardiomyocytedelimited transgenic expression of either a CaMKII inhibitory peptide (AC3-I) or a scrambled control peptide (AC3-C), after 1 mo of Iso treatment. As shown in Fig. 7, Iso treatment increased TBARS, an index of lipid peroxidation, in both AC3-C and AC3-I mice $(A)$, indicating an increase in oxidative stress. However, CaMKII activity, measured by the increase in P-CaMKII and in the phosphorylation of $\mathrm{Thr}^{17}$ site of PLN (Fig. 7, B), and apoptosis, assessed by the increase in TUNEL staining $(C)$ and the ratio $\mathrm{Bax} / \mathrm{Bcl} 2(D)$, only increased in AC3-C mice. Similarly, caspase-3 activation was increased in AC3-C mice treated with Iso by $279 \pm 73.5 \%$ above control, whereas it did not change significantly in Iso-treated AC3-I mice.

These latter results indicate that the increase in ROS that occurred after Iso treatment is upstream of CaMKII activation, and that the kinase activity is directly related to the induction of apoptosis.

\section{DISCUSSION}

ANG II has been shown to be implicated in many cellular physiological and pathological processes. In the long term, the hormone has been associated with cardiomyocyte apoptosis $(27,33,40)$. Moreover, experimental evidence indicates that a critical factor in the transition from compensated to noncompensated cardiac hypertrophy is myocyte cell loss by apoptosis (1), and that the circulating levels of ANG II are increased in heart failure. It has, therefore, been proposed that increased ANG II levels may constitute one of the major triggers for cell death in the transition to heart failure (20). Interestingly, the onset of ANG II plasma or tissue increment during the development of cardiac diseases may start well ahead of the detec- 

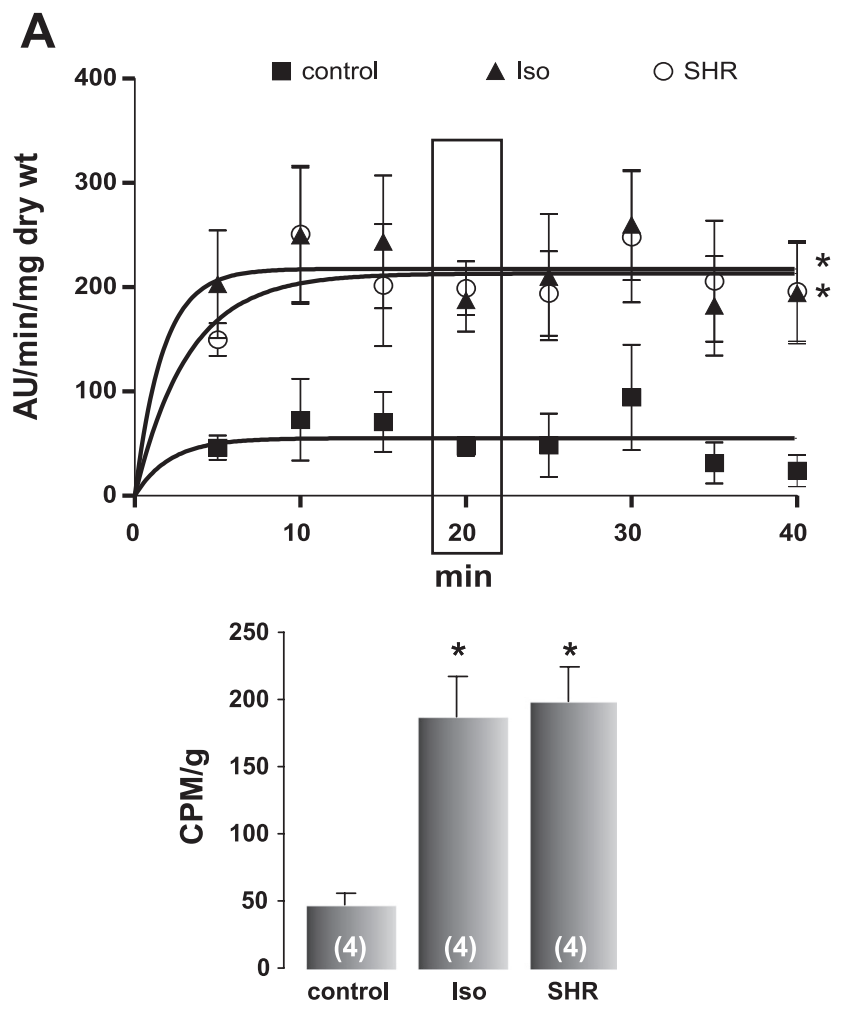

B

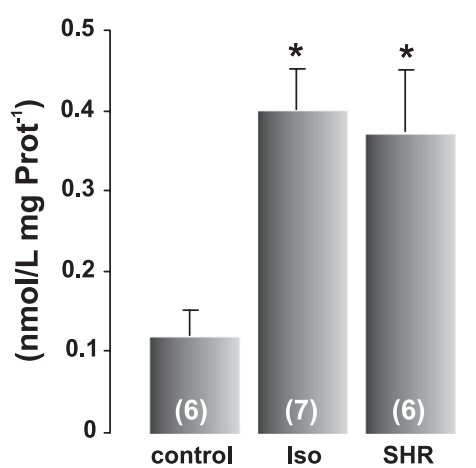

Fig. 6. Superoxide anion $\left(\mathrm{O}_{2}{ }^{-}\right)$and lipid peroxidation are increased in SHR and Iso-rats. $A: \mathrm{O}_{2}{ }^{--}$generation by myocardial slices from control ( $\left.\boldsymbol{\square}\right)$, Iso ( $\boldsymbol{\Delta}$ ), and SHR (O). Both Iso and SHR display a significant increase in $\mathrm{O}_{2} \cdot-$ production. The data fitted with a one-phase exponential association (GraphPad Prism 4.2) from SHR and Iso-rats were significantly higher than the control curve. For better comparison, the bar graph below depicts the mean values at $20 \mathrm{~min}$, when the reaction was completely stabilized, showing a significant increment in $\mathrm{O}_{2}{ }^{-}$- generation in Iso and SHR with respect to control rats. AU, arbitrary units; CPM, counts/min. $B$ : average data of thiobarbituric acid reactive substances (TBARS), indicating that SHR and Iso-rats present higher levels of lipid peroxidation than control rats. Values are means \pm $\mathrm{SE} ; n$, no. of animals in each experimental group (in parentheses). $* P<$ 0.05 vs. control.

tion of cardiac damage. Moreover, tissue concentrations of ANG II are difficult to establish, and they may reach very high levels (over 100 times plasma concentrations) (7) during cardiac remodeling. Thus, to establish the pathophysiological relevance of ANG II using in vitro experimental tools or animals models where ANG II is exogenously administrated is not straightforward and requires in vivo validation. To the best of our knowledge, the in vivo effects of enhanced RAAS at an early stage during the development of heart disease have not been previously studied.

In the present study, we used two different models of heart disease with exacerbated RAAS well before the appearance of signs or symptoms of heart failure. The main conclusions of our results are the following: 1 ) exacerbation of RAAS in these models is an early event necessary to activate CaMKII and to induce cardiac apoptosis; 2) CaMKII activation and cardiomyocyte loss are early signs in the maladaptive processes implicated in the transition from compensated to decompensated LV hypertrophy $(13,22) ; 3)$ activation of CaMKII occurs in vivo without detectable $\left[\mathrm{Ca}^{2+}\right]_{\mathrm{i}}$ increments and is directly related to the increase in ROS and the induction of apoptosis. These results support the contention that ANG IIinduced oxidative stress resets the $\mathrm{Ca}^{2+}$ dependence of CaMKII, as observed in our laboratory's previous in vitro and ex vivo experiments (28).

Animal models. The models used are widely known as cardiac hypertrophy and failure models.

The SHR model is paradigmatic, since it mimics human essential hypertension, and several reports described that endocrine and paracrine RAAS are active $(38,45)$. Although a variety of factors modify aldosterone secretion, ANG II and potassium (43) are the most important regulators. Thus the increased aldosterone plasma levels found in our animals can be taken as an index of ANG II levels, as previously described $(2,45)$.

The Iso-induced cardiac injury model is recognized as one of the toxic cardiomyopathy models of hypertrophy and heart failure $(9,16,34)$. Excessive doses of catecholamines produce diffuse myocardial destruction with myocyte loss and necrosis, as well as extensive fibrosis in animals and in patients. This kind of damage may also be seen in patients with pheochromocytoma (37). In this model, an exacerbation of RAAS was previously described (16) and confirmed by the present results.

In the present work, we used these two models of enhanced RAAS at an early stage of disease, as evident by the significant degree of hypertrophy without heart failure signs.

The early signs of heart disease. Typically, heart failure is the culmination of long-standing diseases, such as hypertension, ischemia from atherosclerosis, viral myocarditis, valvular insufficiency, or mutations in genes encoding sarcomeric proteins $(2,25)$. Besides contractile disturbances of cardiomyocytes and interstitial and perivascular fibrosis, cardiomyocyte loss is now being considered as one of the determinant factors of the maladaptive events that negatively impacts the myocardium and its propensity toward failure (12). Although the apoptotic rate observed in the present results is low, rodent studies have implicated low rates of cardiac myocyte apoptosis in the pathogenesis of heart failure. For instance, it has been previously shown that an apoptotic rate as low as $0.023 \%$ is sufficient to cause a lethal, dilated cardiomyopathy within 8-24 wk in transgenic mice with cardiac-restricted expression of an inducible caspase-8 allele (41). There is no information concerning the magnitude of cell loss required to depress cardiac contractility in the hypertrophied human heart when cell death occurs (15). Indeed, the apoptotic process takes at most $24 \mathrm{~h}$ to be completed, and heart failure is a condition that only manifests itself after many years. Thus it is conceivable that chronic loss of small number of cardiomyocytes on a daily 
A

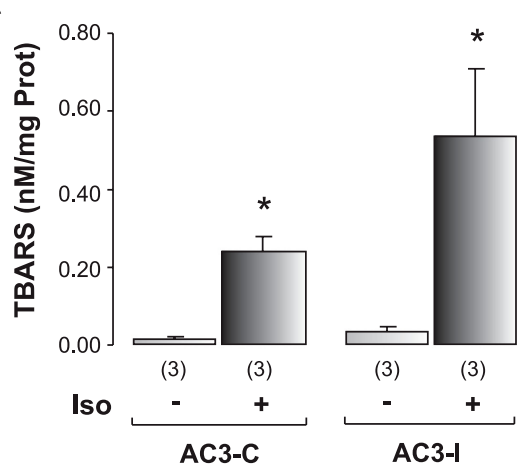

B
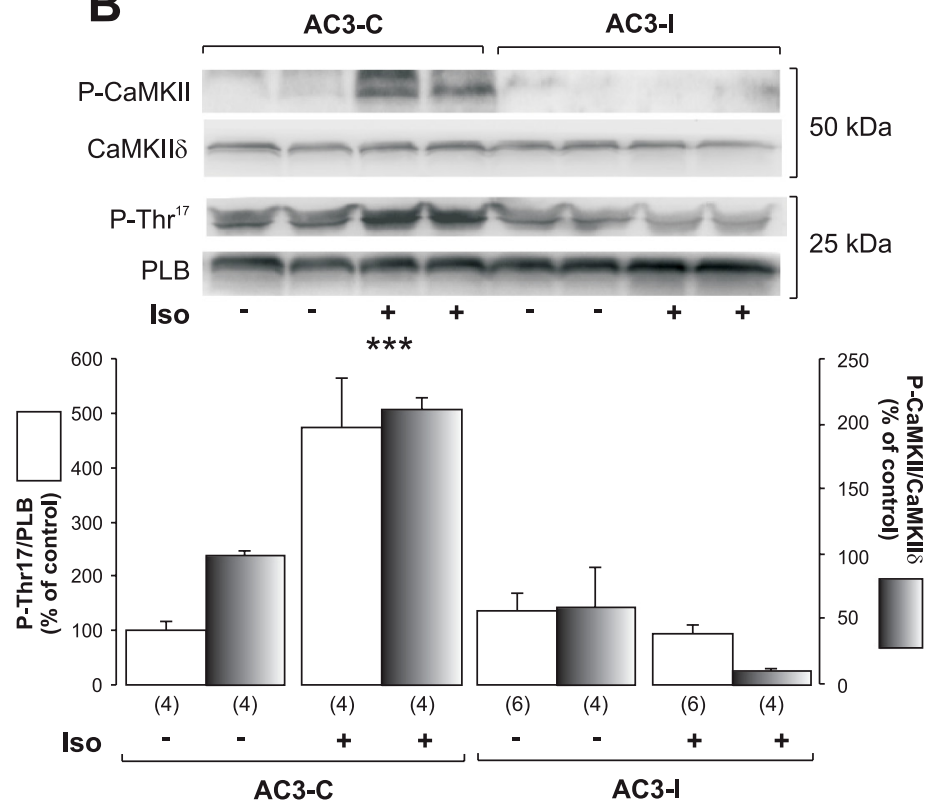

$25 \mathrm{kDa}$
C

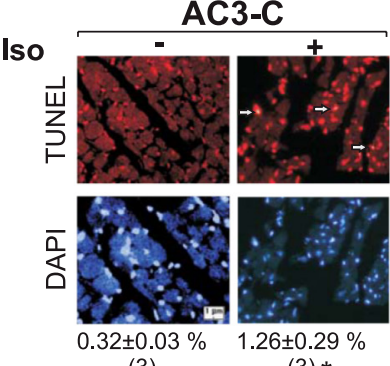

(3)
(3) *

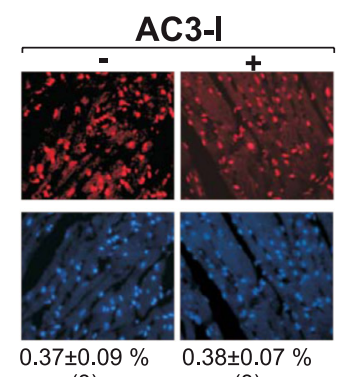

(3)

(3)
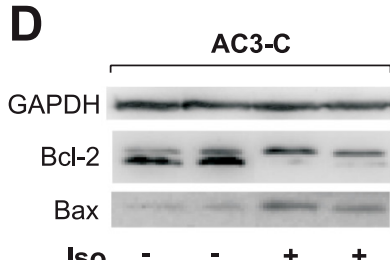

AC3-I

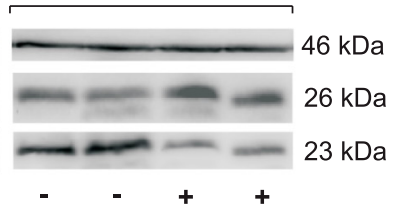

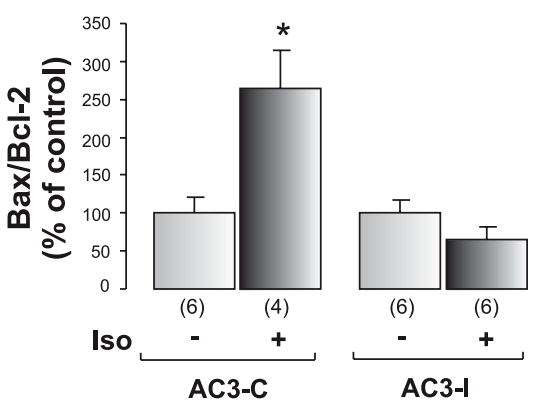

Fig. 7. Mice with cardiomyocyte-delimited transgenic expression of CaMKII inhibitory peptide are protected from Iso-induced apoptosis. A: lipid peroxidation measured by TBARS indicates that Iso treatment increases oxidative stress in both AC3-C and AC3-I mice. B: representative blots from P-CaMKII and P-Thr ${ }^{17}$, and their respective total proteins, as an index of CaMKII activity, and average results, show that, under Iso treatment, only AC3-C mice increase phosphorylation of CaMKII and PLN at the CaMKII site. C: TUNEL and DAPI photographs of the different groups and mean (SE) values of these experiments, indicating a significant increment in TUNEL-positive cells normalized by total DAPI stained nuclei only in the AC3-C mice treated with Iso (***). D: typical blots of proand anti-apoptotic protein Bax, and Bcl-2, and mean $( \pm \mathrm{SE})$ results in the bar graph below. GAPDH signals were used as loading controls. Iso treatment induced apoptosis only in AC3-C mice. $* P<0.05$ vs. other groups. $* * * P<0.001$ vs. other groups.

basis can have dramatic consequences on myocardial integrity (36). Moreover, myocardial apoptosis is evident in the myocardium before the occurrence of ventricular dilation and the development of symptoms, which suggests that apoptosis is a causative mechanism rather than a consequence of failure (14). The present results reveal that the increase in apoptotic death, as well as the enhanced activity of CaMKII, are early events in these and probably other models with exacerbated RAAS. Since apoptosis paralleled hypertrophy in these two models, the results may indicate that apoptosis represents either an early step in the evolution to heart failure being involved in cardiac remodeling or a mechanism tending to compensate the development of hypertrophy. Further studies are currently on course to discriminate between these possibilities.

$\mathrm{Ca}^{2+}$ vs. ROS and the role of CaMKII in cardiac disease. CaMKII is typically activated by increments in $\left[\mathrm{Ca}^{2+}\right]_{\mathrm{i}}$ and calmodulin $\left(\mathrm{Ca}^{2+} / \mathrm{Cam}\right)$. The complex $\mathrm{Ca}^{2+} / \mathrm{Cam}$ promotes a conformational change that relieves the autoinhibitory effect of the regulatory domain on the kinase, activating the enzyme. In the sustained presence of $\mathrm{Ca}^{2+} / \mathrm{Cam}$, CaMKII undergoes intersubunit autophosphorylation, resulting in $\mathrm{Ca}^{2+} / \mathrm{Cam}$-independent activity. Recent experimental evidence indicated that ROS-induced oxidation of methionine residues is able to sustain CaMKII activity in the absence of $\mathrm{Ca}^{2+} / \mathrm{CaM}$. This action requires, however, previous binding of $\mathrm{Ca}^{2+} / \mathrm{Cam}$ to expose the autoinhibitory domain of CaMKII for oxidation (11). Interestingly, in a previous study, our laboratory concluded that ROS resets the dependence of CaMKII to $\mathrm{Ca}^{2+}$ to extremely low $\left[\mathrm{Ca}^{2+}\right]_{\mathrm{i}}$ levels (28). The present results obtained in two different in vivo models are consistent with these previous findings, since the increased activity of CaMKII occurred in the absence of any detectable increase in $\left[\mathrm{Ca}^{2+}\right]_{\mathrm{i}}$, but in the presence of a significant increase in ROS production. Our results in transgenic mice further indicate that ROS production is upstream of CaMKII activation in the cascade of events that produces apoptosis after Iso treatment. In this 
context, it is worthwhile to mention that ROS-induced phosphatase inhibition could also contribute to sustained CaMKII activation in vivo (19).

Perspectives. The present results clearly indicate that activation of CaMKII and the associated apoptosis are very early events in the development of heart disease that are evident even when the only manifestation of the injury is the presence of hypertrophy, without any sign or symptom of cardiac dysfunction. They further show that CaMKII activity and apoptosis can both be prevented by inhibition of RAAS. Whether the data can be extrapolated to humans remains to be shown. However, the apoptotic rate obtained in the present results is much lower than the one measured in cardiac tissue from patients with end-stage heart failure, suggesting that apoptosis may also be a causal mechanism of human heart failure. If so, cardiac myocyte apoptosis and CaMKII may constitute novel targets for therapies directed against heart failure. Moreover, in the context of hypertrophy and hypertension, activation of CaMKII could be considered an early index of bad prognosis.

\section{ACKNOWLEDGMENTS}

The excellent technical assistance of Andrés Pinilla in echocardiographic imaging is gratefully acknowledged. The assistance of Karina Porzio and Laura Suarez for RIA determinations is also acknowledged.

\section{GRANTS}

This work was supported by Fogarty Grant R03 TW07713 (National Institutes of Health), PICT 26117 from Agencia Nacional de Promoción Científica y Tecnológica, and PIP 2139 from Consejo Nacional de Investigaciones Científicas y Técnicas to A. Mattiazzi; and PICT 1041 from Agencia Nacional de Promoción Científica y Tecnológica to J. Palomeque.

\section{DISCLOSURES}

No conflicts of interest, financial or otherwise, are declared by the author(s).

\section{AUTHOR CONTRIBUTIONS}

J.O.V.R. and J.P. performed experiments; J.O.V.R. and J.P. analyzed data; J.O.V.R., J.P., and A.M. interpreted results of experiments; J.O.V.R. and J.P. prepared figures; J.O.V.R., J.P., and A.M. approved final version of manuscript; J.P. and A.M. conception and design of research; J.P. and A.M. drafted manuscript; J.P. and A.M. edited and revised manuscript.

\section{REFERENCES}

1. Adams JW, Pagel AL, Means CK, Oksenberg D, Armstrong RC, Brown JH. Cardiomyocyte apoptosis induced by Galphaq signaling is mediated by permeability transition pore formation and activation of the mitochondrial death pathway. Circ Res 87: 1180-1187, 2000.

2. Adams KF Jr. New epidemiologic perspectives concerning mild-tomoderate heart failure. Am J Med 110, Suppl 7A: 6S-13S, 2001.

3. Beznak M. Hemodynamics during the acute phase of myocardial damage caused by isoproterenol. Can J Biochem Physiol 40: 25-30, 1962.

4. Beznak M, Hacker P. Hemodynamics during the chronic stage of myocardial damage caused by isoproterenol. Can J Physiol Pharmacol 42: 269-274, 1964.

5. Buege JA, Aust SD. Microsomal lipid peroxidation. Methods Enzymol 52: 302-310, 1978.

6. Cook SA, Sugden PH, Clerk A. Regulation of bcl-2 family proteins during development and in response to oxidative stress in cardiac myocytes: association with changes in mitochondrial membrane potential. Circ Res 85: 940-949, 1999.

7. Dell'Italia LJ, Meng QC, Balcells E, Wei CC, Palmer R, Hageman GR, Durand J, Hankes GH, Oparil S. Compartmentalization of angiotensin II generation in the dog heart. Evidence for independent mechanisms in intravascular and interstitial spaces. J Clin Invest 100: 253-258, 1997.
8. Dikalov S, Griendling KK, Harrison DG. Measurement of reactive oxygen species in cardiovascular studies. Hypertension 49: 717-727, 2007.

9. El-Demerdash E, Awad AS, Taha RM, El-Hady AM, Sayed-Ahmed MM. Probucol attenuates oxidative stress and energy decline in isoproterenol-induced heart failure in rat. Pharmacol Res 51: 311-318, 2005.

10. Erickson JR, He BJ, Grumbach IM, Anderson ME. CaMKII in the cardiovascular system: sensing redox states. Physiol Rev 91: 889-915, 2011

11. Erickson JR, Joiner ML, Guan X, Kutschke W, Yang J, Oddis CV, Bartlett RK, Lowe JS, O'Donnell SE, Aykin-Burns N, Zimmerman MC, Zimmerman K, Ham AJ, Weiss RM, Spitz DR, Shea MA, Colbran RJ, Mohler PJ, Anderson ME. A dynamic pathway for calcium-independent activation of CaMKII by methionine oxidation. Cell 133: 462-474, 2008.

12. Foo RS, Mani K, Kitsis RN. Death begets failure in the heart. J Clin Invest 115: 565-571, 2005.

13. Frohlich ED. State of the Art lecture. Risk mechanisms in hypertensive heart disease. Hypertension 34: 782-789, 1999.

14. Galiuto L, Lotrionte M, Crea F, Anselmi A, Biondi-Zoccai GG, De Giorgio F, Baldi A, Baldi F, Possati G, Gaudino M, Vetrovec GW, Abbate A. Impaired coronary and myocardial flow in severe aortic stenosis is associated with increased apoptosis: a transthoracic Doppler and myocardial contrast echocardiography study. Heart 92: 208-212, 2006.

15. Gonzalez A, Fortuno MA, Querejeta R, Ravassa S, Lopez B, Lopez N, Diez J. Cardiomyocyte apoptosis in hypertensive cardiomyopathy. Cardiovasc Res 59: 549-562, 2003.

16. Grimm D, Elsner D, Schunkert H, Pfeifer M, Griese D, Bruckschlegel G, Muders F, Riegger GA, Kromer EP. Development of heart failure following isoproterenol administration in the rat: role of the renin-angiotensin system. Cardiovasc Res 37: 91-100, 1998.

17. Hagemann D, Bohlender J, Hoch B, Krause EG, Karczewski P. Expression of $\mathrm{Ca}^{2+} /$ calmodulin-dependent protein kinase II delta-subunit isoforms in rats with hypertensive cardiac hypertrophy. Mol Cell Biochem 220: 69-76, 2001.

18. Hare JM. Oxidative stress and apoptosis in heart failure progression. Circ Res 89: 198-200, 2001.

19. Howe CJ, Lahair MM, McCubrey JA, Franklin RA. Redox regulation of the calcium/calmodulin-dependent protein kinases. J Biol Chem 279: 44573-44581, 2004.

20. Kajstura J, Cigola E, Malhotra A, Li P, Cheng W, Meggs LG, Anversa P. Angiotensin II induces apoptosis of adult ventricular myocytes in vitro. J Mol Cell Cardiol 29: 859-870, 1997.

21. Kramer RE, Robinson TV, Schneider EG, Smith TG. Direct modulation of basal and angiotensin II-stimulated aldosterone secretion by hydrogen ions. J Endocrinol 166: 183-194, 2000.

22. Levy D, Garrison RJ, Savage DD, Kannel WB, Castelli WP. Prognostic implications of echocardiographically determined left ventricular mass in the Framingham Heart Study. N Engl J Med 322: 1561-1566, 1990.

23. Ling YH, Liebes L, Ng B, Buckley M, Elliott PJ, Adams J, Jiang JD, Muggia FM, Perez-Soler R. PS-341, a novel proteasome inhibitor, induces Bcl-2 phosphorylation and cleavage in association with G2-M phase arrest and apoptosis. Mol Cancer Ther 1: 841-849, 2002.

24. Litwin SE, Katz SE, Weinberg EO, Lorell BH, Aurigemma GP, Douglas PS. Serial echocardiographic-Doppler assessment of left ventricular geometry and function in rats with pressure-overload hypertrophy. Chronic angiotensin-converting enzyme inhibition attenuates the transition to heart failure. Circulation 91: 2642-2654, 1995.

25. Lloyd-Jones DM, Larson MG, Leip EP, Beiser A, D'Agostino RB, Kannel WB, Murabito JM, Vasan RS, Benjamin EJ, Levy D. Lifetime risk for developing congestive heart failure: the Framingham Heart Study. Circulation 106: 3068-3072, 2002.

26. Mundina-Weilenmann C, Vittone L, Ortale M, de Cingolani GC, Mattiazzi A. Immunodetection of phosphorylation sites gives new insights into the mechanisms underlying phospholamban phosphorylation in the intact heart. J Biol Chem 271: 33561-33567, 1996.

27. Palomeque J, Delbridge L, Petroff MV. Angiotensin II: a regulator of cardiomyocyte function and survival. Front Biosci 14: 5118-5133, 2009.

28. Palomeque J, Rueda OV, Sapia L, Valverde CA, Salas M, Petroff MV, Mattiazzi A. Angiotensin II-induced oxidative stress resets the $\mathrm{Ca}^{2+}$ dependence of $\mathrm{Ca}^{2+}$-calmodulin protein kinase II and promotes a death pathway conserved across different species. Circ Res 105: 1204-1212, 2009.

29. Palomeque J, Sapia L, Hajjar RJ, Mattiazzi A, Vila Petroff M. Angiotensin II-induced negative inotropy in rat ventricular myocytes: role 
of reactive oxygen species and p38 MAPK. Am J Physiol Heart Circ Physiol 290: H96-H106, 2006.

30. Rona G, Chappel CI, Balazs T, Gaudry R. An infarct-like myocardial lesion and other toxic manifestations produced by isoproterenol in the rat. AMA Arch Pathol 67: 443-455, 1959.

31. Sahn DJ, DeMaria A, Kisslo J, Weyman A. Recommendations regarding quantitation in M-mode echocardiography: results of a survey of echocardiographic measurements. Circulation 58: 1072-1083, 1978.

32. Salas MA, Valverde CA, Sanchez G, Said M, Rodriguez JS, Portiansky EL, Kaetzel MA, Dedman JR, Donoso P, Kranias EG, Mattiazzi A. The signalling pathway of CaMKII-mediated apoptosis and necrosis in the ischemia/reperfusion injury. J Mol Cell Cardiol 48: 1298-1306, 2010.

33. Sorescu D, Griendling KK. Reactive oxygen species, mitochondria, and $\mathrm{NAD}(\mathrm{P}) \mathrm{H}$ oxidases in the development and progression of heart failure. Congest Heart Fail 8: 132-140, 2002.

34. Teerlink JR, Pfeffer JM, Pfeffer MA. Progressive ventricular remodeling in response to diffuse isoproterenol-induced myocardial necrosis in rats. Circ Res 75: 105-113, 1994.

35. Tojo A, Onozato ML, Kobayashi N, Goto A, Matsuoka H, Fujita T. Angiotensin II and oxidative stress in Dahl Salt-sensitive rat with heart failure. Hypertension 40: 834-839, 2002.

36. van Empel VP, Bertrand AT, Hofstra L, Crijns HJ, Doevendans PA, De Windt LJ. Myocyte apoptosis in heart failure. Cardiovasc Res 67: 21-29, 2005.

37. Van Vliet PD, Burchell HB, Titus JL. Focal myocarditis associated with pheochromocytoma. N Engl J Med 274: 1102-1108, 1966.

38. Varagic J, Frohlich ED. Local cardiac renin-angiotensin system: hypertension and cardiac failure. J Mol Cell Cardiol 34: 1435-1442, 2002.

39. Vila-Petroff M, Salas MA, Said M, Valverde CA, Sapia L, Portiansky E, Hajjar RJ, Kranias EG, Mundina-Weilenmann C, Mattiazzi A.
CaMKII inhibition protects against necrosis and apoptosis in irreversible ischemia-reperfusion injury. Cardiovasc Res 73: 689-698, 2007.

40. Vivar R, Soto C, Copaja M, Mateluna F, Aranguiz P, Munoz JP, Chiong M, Garcia L, Letelier A, Thomas WG, Lavandero S, DiazAraya G. Phospholipase C/protein kinase C pathway mediates angiotensin II-dependent apoptosis in neonatal rat cardiac fibroblasts expressing AT1 receptor. J Cardiovasc Pharmacol 52: 184-190, 2008.

41. Wencker D, Chandra M, Nguyen K, Miao W, Garantziotis S, Factor SM, Shirani J, Armstrong RC, Kitsis RN. A mechanistic role for cardiac myocyte apoptosis in heart failure. J Clin Invest 111: 1497-1504, 2003.

42. Whelan RS, Kaplinskiy V, Kitsis RN. Cell death in the pathogenesis of heart disease: mechanisms and significance. Annu Rev Physiol 72: 19-44, 2010.

43. Williams GH. Aldosterone biosynthesis, regulation, and classical mechanism of action. Heart Fail Rev 10: 7-13, 2005.

44. Yamamoto K, Ichijo H, Korsmeyer SJ. BCL-2 is phosphorylated and inactivated by an ASK1/Jun N-terminal protein kinase pathway normally activated at G(2)/M. Mol Cell Biol 19: 8469-8478, 1999.

45. Yoneda M, Sanada H, Yatabe J, Midorikawa S, Hashimoto S, Sasaki M, Katoh T, Watanabe T, Andrews PM, Jose PA, Felder RA. Differential effects of angiotensin II type-1 receptor antisense oligonucleotides on renal function in spontaneously hypertensive rats. Hypertension 46: $58-65,2005$.

46. Zhang T, Brown JH. Role of $\mathrm{Ca}^{2+} /$ calmodulin-dependent protein kinase II in cardiac hypertrophy and heart failure. Cardiovasc Res 63: 476-486, 2004.

47. Zhu W, Woo AY, Yang D, Cheng H, Crow MT, Xiao RP. Activation of CaMKIIdeltaC is a common intermediate of diverse death stimuliinduced heart muscle cell apoptosis. J Biol Chem 282: 10833-10839, 2007.

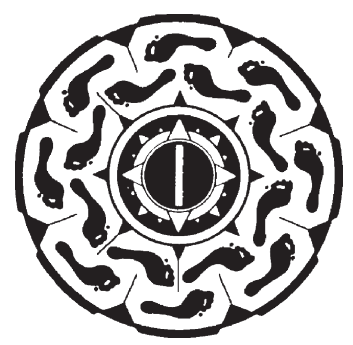

